\title{
Large Eddy Simulation and Flow Field Analysis of Car on the Bridge under Turbulent Crosswind
}

\author{
Juyue Ding $\mathbb{D},{ }^{1}$ Weitan Yin, $^{2}$ and Yongqi Ma $\mathbb{D}^{1}$ \\ ${ }^{1}$ School of Mechanics and Engineering Science, Shanghai University, Shanghai Institute of Applied Mathematics and Mechanics, \\ Shanghai 200444, China \\ ${ }^{2}$ Institute of Sound and Vibration Research, Human Sciences Group, SO17 1BJ, Southampton, UK \\ Correspondence should be addressed to Yongqi Ma; mayongqi@shu.edu.cn
}

Received 26 March 2020; Revised 8 May 2020; Accepted 1 April 2021; Published 19 April 2021

Academic Editor: Yumin Cheng

Copyright (C) 2021 Juyue Ding et al. This is an open access article distributed under the Creative Commons Attribution License, which permits unrestricted use, distribution, and reproduction in any medium, provided the original work is properly cited.

\begin{abstract}
As more long-span bridges continue to be completed and opened to traffic, the safety of cars driving across the bridge has attracted more and more attention, especially when the car is suddenly affected by the crosswind, the car is likely to have direction deviation or even a rollover accident. In this paper, the large eddy simulation method is used to study the flow field characteristics and safety of the car on the bridge under the turbulent crosswind. The numerical simulation model is established by referring to the Donghai Bridge, and the correctness of the car model is validated by combining with the data of wind tunnel test. The influence of factors such as the porosity and height of the bridge guardrail and the Reynolds number of airflow on the flow field characteristics is analyzed. The study shows that, in order to ensure the safety of cars on the bridge, the bridge guardrail porosity should be small, $35.8 \%$ is more suitable, the guardrail height should be more suitable within the range of 1.5-1.625 meters, and the Reynolds number should not be $3.51 e+5$. The research results of this paper will provide reference for the optimal design of bridge guardrail.
\end{abstract}

\section{Introduction}

High-speed cars are always affected by the natural crosswinds when they are meeting trucks, driving out of a tunnel, and passing a bridge. The cars' driving states will be interfered by the crosswinds, which may produce a side lurching, cross velocity, and yaw velocity. As a result, the cars may deviate from their original route, and the drivers may have to manipulate their steering wheels to keep the cars running straight. In recent car designs, the light weight car and aerodynamic drag have been highly emphasized in order to a better fuel economy. A crosswind will produce high pressure on the windward side and low pressure on the leeward side of a car, especially in the front. It may produce a yaw moment that tends to rotate the car [1]. A more fuelsaving design moves the pressure center forward, which makes a car more likely to deviate from its original path. Thus, the car will have more unstable behavior.

With the construction of more and more sea crossing bridges around the world, this problem seems more important now [2]. Over the past few decades, many car accidents have been caused by crosswind gusts. Traffic accidents can cause casualties, traffic jams, and economic losses. Such as, on August 11, 2004, seven moving cars on the Chinese Humen Suspension Bridge were swayed by crosswind. In order to prevent these accidents, experts recommend installing windshields or taking traffic control measurements to protect cars from high-speed crosswinds. These measures can effectively improve the safety of car driving on the bridge under a crosswind. However, overdesigned windshields or overcomplex traffic control guides may have negative impacts on the aerodynamic stability of a car and the bridge. Therefore, it is necessary to study the aerodynamics of cars driving on bridges with all-sided consideration of the surrounding environment and structures.

In aerodynamic simulation of the engineering problems, the numerical simulation method has developed greatly from the finite element method [3] to meshless method. In recent years, researchers have made a lot of outstanding 
work [4-6]. The meshless method has been developed for solving various engineering problems $[7,8]$. Liu et al. researched on the functionally graded materials using the meshless method [9]. About the driving car problem, Wang et al. studied aerodynamics by the CFD coupling method [10]. Maruyama and Yamazaki added a driver model based on experimental results to the safety analysis of road cars [11]; meanwhile, they used crosswind gusts instead of the actual wind load applied to cars crossing bridges. The effects of the bridge movement at the pylon position on car safety were neglected $[12,13]$. Cheli et al. obtained the aerodynamic admittance function and the aerodynamics of road cars driving on flat terrain, viaducts, and embankments [14]. The turbulent wind fields around the car models were studied based on the quasi-steady state theory [15]. Cheung and Chan established a single-car accident assessment model, considering the coupling effects between cars and dangerous driving conditions in 2010 [16]. Sigbjörnsson and Snæbjörnsson proposed a probability analysis model [17]. $\mathrm{Xu}$ and Guo took account of road surface roughness and car suspension systems and studied car safety under crosswinds [18]. Chen et al. and Krid et al. conducted a wide research on the rollover prevention and detection of active braking systems (ABS for short), active suspensions, active stabilizers, and so on $[19,20]$. There are also many control methods like active front steering (AFS), which has been used to reduce the roll rate and lateral acceleration when the car is turning [21].

There are two approaches to reduce the impact of crosswinds on moving cars: one is regulating the car speed [22] and the other is installing windproof facilities [23]. Airtight and porous windbreaks have been widely used to reduce the influences of crosswinds on pedestrians and buildings [24], but those facilities cannot be applied to long-span bridges. Based on this, this paper mainly studies the safety of the car driving on bridge under the turbulent crosswind and the influence of bridge guardrail on the safety of the car. The turbulent large eddy simulation (LES) numerical method is used to simulate the flow field around the car and bridge guardrail. The influence of different porosities and heights of bridge guardrail and the influence of crosswind under different Reynolds numbers on the lateral force and lift force of the car are calculated and analyzed in order to put forward the corresponding reference to the safety measures and schemes of driving car on the bridge.

\section{Computation Equation}

Over the past few decades, some researchers simulated the crosswinds with gust generators because it is very hard to measure the parameters of a car under a crosswind by a wind tunnel test. Although this method is widely used by researchers all over the world, the results have uncertainties due to many kinds of objective factors. Additionally, this method produces great danger in operation, and the cost is relatively high. In contrast, numerical simulations can not only obtain relatively stable results but also greatly reduce the risk and cost.
The large eddy simulation (LES) is a compromise between direct numerical simulation and turbulent modeling theory, which requires less computational cost and has higher calculation accuracy. In this paper, the large eddy simulation model as a numerical method is adopted. Since the speed of a car is much lower than that of sound, the Mach number of the flow is much less than 0.3 and the Reynolds number can only reach up to $1 \times 10^{7}$; additionally, the influence of the heat exchange with the outside world is neglected, and the entire mathematical model can be expressed as an incompressible, adiabatic three-dimensional turbulent model. The crosswind motion is divided into two parts, including large-scale motion and small-scale motion. The relationships between small-scale quantities and large-scale quantities are established through the model.

2.1. Large Eddy Simulation (LES). The LES is a mathematical turbulence model which reduces the range of length scales of the solution by applying 'low pass filtering' to the Navier-Stokes equations, eliminating the small scales and thus reducing the computational cost of the simulation. Denoting the resolved filtered velocity and pressure as $\bar{u}_{i}$ and $\bar{p}_{i}$, the governing equations for LES are as follows:

$$
\begin{gathered}
\frac{\partial \overline{u_{i}}}{\partial x_{i}}=0 \\
\frac{\partial \overline{u_{i}}}{\partial t}+\frac{\partial}{\partial x_{j}}\left(\overline{u_{i} u_{j}}\right)=-\frac{1}{\rho} \frac{\partial \bar{P}}{\partial x_{i}}+v \frac{\partial^{2} \overline{u_{i}}}{\partial x_{j} \partial x_{j}}-\frac{\partial \tau_{i j}}{\partial x_{j}} .
\end{gathered}
$$

Here, $u_{i}$ and $P$ represent the velocity components and the pressure, when $i, j=1,2,3$ which represent $x, y, z$ three directions. The bar above the variable represents the grid filtering operation. The Sub Grid Scale (SGS) stress tensor $\tau_{i j}=\overline{u_{i} u_{j}}-\overline{u_{i} u_{j}}$ contains the influence of the small scales on the large energy scales in equation (2). The original eddy viscosity model proposed by Smagorinsky [25] will be used for its simplicity and lower computational cost. This method assumes that dissipation and energy production of the small scales are balanced. The anisotropic part of the SGS stress sensor is represented as

$$
\tau_{i j}-\frac{1}{3} \delta_{i j} \tau_{k k}=-2 v_{s g s} \bar{S}_{i j},
$$

where $v_{s g s}=\left(C_{s} f \Delta\right)^{2}|\bar{S}|$ being the SGS viscosity, and

$$
S_{i j}=\frac{1}{2}\left(\frac{\partial \bar{u}_{i}}{\partial x_{j}}+\frac{\partial \bar{u}_{j}}{\partial x_{i}}\right)
$$

which is the resolved rate-of-strain tensor, $|\bar{S}|=\left(2 \bar{S}_{i j} \bar{S}_{i j}\right)^{1 / 2}$, and $f$ is the van Driest damping function given as follows:

$$
f=1-\exp \left(\frac{n^{+}}{25}\right)
$$

with $n$ is the wall normal distance. This function allows to partially take in account the wall effects by damping length scale $l=C_{s} \Delta$ near the walls. The value of $C=0.1$ is normally 
used. Filter width $\Delta$ is defined as $\Delta=\left(\Delta_{1} \Delta_{2} \Delta_{3}\right)^{1 / 3}$, where the subscripts 1,2 , and 3 refer to the computational cell size in the three coordinate directions.

2.2. Load Equation of the Car on the Bridge. The car moving on the bridge is subjected to force and the moment of the airflow around the bridge. The force and the moment depend on the speed and structure of the car. With the advancement of modern technology, the car manufacturing process is gradually improving. The shapes of cars have also transformed from horizontal and vertical types to streamlined types. Although streamlined cars seem more elegant and lower wind resistant, it should be mentioned that the stability of a lower wind resistance car sometimes gets worse stability under a crosswind.

The force and moment on the car have been divided into three orthogonal component forces and three moments in the cartesian coordinates system. As shown in Figure 1, under the asymmetric airflow $(\beta \neq 0)$, the car is subjected to the aerodynamic $\operatorname{drag} F_{x}$, the aerodynamic lateral force $F_{y}$, the aerodynamic lift $F_{z}$, the roll moment $M_{x}$ around the $x$ axis, the trim moment $M_{y}$ around the $y$ axis, and the yaw moment $M_{z}$ around the $z$ axis.

A large number of experiments have confirmed that the magnitude of the aerodynamic force on a car is proportional to the square of the relative velocity, the projected area of the windward surface, and the aerodynamic coefficient of the car. The magnitude of the aerodynamic moment is proportional to the square of the relative velocity, the projected area of the windward surface, the wheelbase of the car, and the aerodynamic coefficient of the car. The aerodynamic force and the aerodynamic moment are usually expressed by the following equations:

$$
\begin{aligned}
F_{x} & =\frac{1}{2} \rho A V_{\infty}^{2} C_{D}, \\
F_{y} & =\frac{1}{2} \rho A V_{\infty}^{2} C_{S}, \\
F_{z} & =\frac{1}{2} \rho A V_{\infty}^{2} C_{L}, \\
M_{x} & =\frac{1}{2} \rho A a V_{\infty}^{2} C_{M x}, \\
M_{y} & =\frac{1}{2} \rho A a V_{\infty}^{2} C_{M y}, \\
M_{z} & =\frac{1}{2} \rho A a V_{\infty}^{2} C_{M z},
\end{aligned}
$$

where $C_{D}, C_{S}$, and $C_{L}$ are the aerodynamic drag coefficient, the aerodynamic lateral coefficient, and the aerodynamic lift coefficient; $C_{M_{x}}, C_{M_{y}}$, and $C_{M_{z}}$ are the aerodynamic roll moment coefficient, the aerodynamic trim moment coefficient, and the aerodynamic yaw moment coefficient, and all are dimensionless; $A$ represents the projected area of a car's windward side in $\mathrm{m}^{2} ; \rho$ is the density of air, usually taken as $1.225 \mathrm{~kg} / \mathrm{m}^{3} ; V_{\infty}$ represents the relative velocity of the

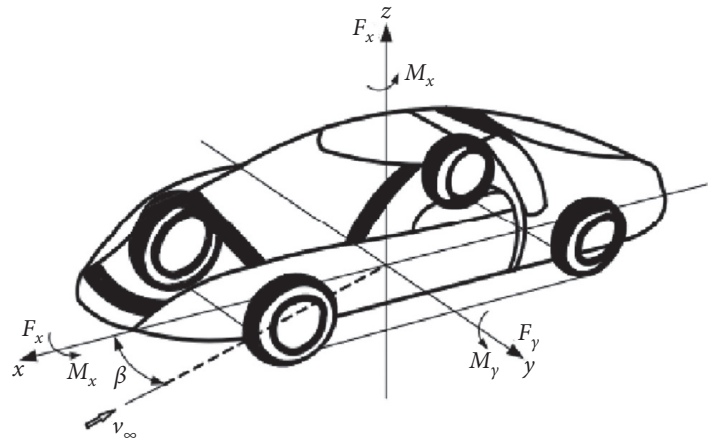

Figure 1: The forces and moments on the car.

resultant airflow, which is the resultant velocity of the car and the lateral wind velocity in $\mathrm{m} / \mathrm{s}$; and $a$ is the car wheelbase.

\section{Aerodynamic Simulation Model}

3.1. The Car Model and Validation. According to the wind tunnel test of the car, the numerical simulation model of a car is built. The car is placed in the wind tunnel test space with a size of $20 \mathrm{~m} \times 13 \mathrm{~m} \times 8 \mathrm{~m}$. In this numerical simulation model, some parts of the car have to been simplified. The wipers on the front windshield and the rearview mirrors are simplified in order to prevent some mesh deformation that makes the result in large errors during the generation of the grid. Six boundaries are set, including up, down, right, left, front, and back sides. The front boundary is set as the velocity inlet, the back boundary is set as the pressure outlet, and the ground is set as the slip plane. The car model and the wind tunnel model are shown in Figures 2 and 3 .

Through numerical simulation computation, the distribution of pressure over the car is given as shown in Figure 4:

In Figure 4, the maximum pressure over the car is $675.9 \mathrm{~Pa}$, the aerodynamic drag coefficient is 0.337 , the aerodynamic lift coefficient is 0.144 , and the aerodynamic drag and lift forces are $443.3 \mathrm{~N}$ and $190.1 \mathrm{~N}$, without the influence of other factors. Table 1 indicates that the errors between the simulation results and the wind tunnel test data are less than $10 \%$. The results of the numerical simulation and the wind tunnel test are fitting well, which shows that this numerical simulation model of the car is reliable and accurate, and can be used for following research.

3.2. Simulation of the Bridge and Crosswind Load. About simulation of the bridge, the Donghai Bridge is taken as a reference. The total length of the Donghai Bridge is $32.5 \mathrm{~km}$, located in the northern part of Hangzhou Bay, and is an auxiliary project of the Yangshan deep-water port area. The weather in that area is complex and extremely changeable; typhoons, tornadoes, and paroxysmal small-scale disasters happen often. The annual maximum wind speed can reach $27 \mathrm{~m} / \mathrm{s}$. Strong winds, especially crosswinds, may increase the lift force and the lateral force, the rise of which is dangerous to 


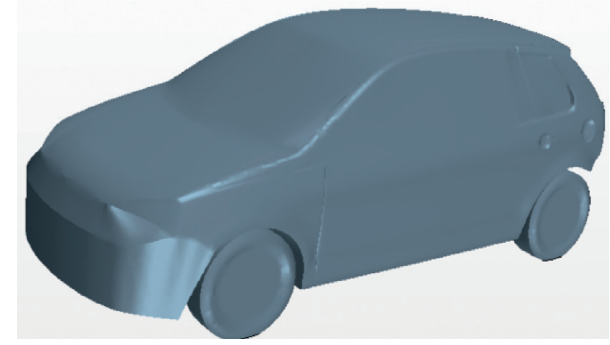

Figure 2: Car model.

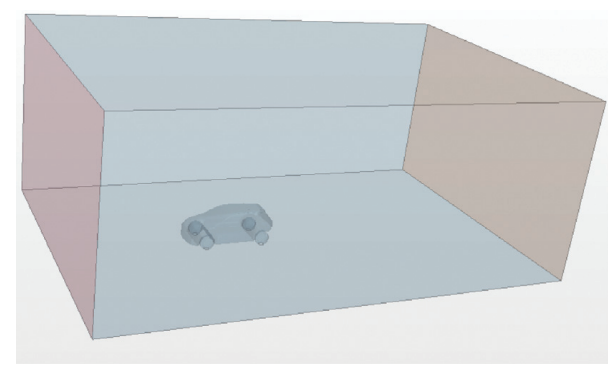

Figure 3: Wind tunnel test model.

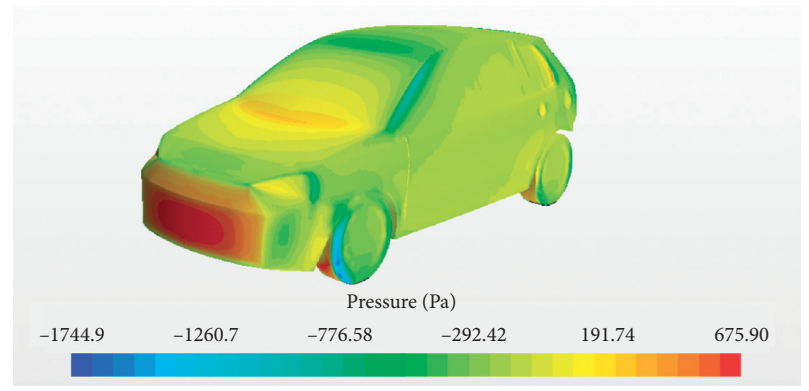

FIgURE 4: The distribution of pressure over the car.

TABle 1: Comparison between the wind tunnel test and the numerical simulation.

\begin{tabular}{lccc}
\hline & $\begin{array}{c}\text { Wind tunnel } \\
\text { test }\end{array}$ & $\begin{array}{c}\text { Numerical } \\
\text { simulation }\end{array}$ & $\begin{array}{c}\text { Errors } \\
(\%)\end{array}$ \\
\hline $\begin{array}{l}\text { Maximum pressure } \\
(\mathrm{Pa})\end{array}$ & 637.0 & 675.9 & 6.1 \\
$\begin{array}{l}\text { Aerodynamic drag } \\
\text { force }(N)\end{array}$ & 468.5 & 443.3 & 5.4 \\
$\begin{array}{l}\text { Aerodynamic lift force } \\
(N)\end{array}$ & 180.6 & 190.1 & 5.3 \\
$\begin{array}{l}\text { Drag coefficient } \\
\text { Lift coefficient }\end{array}$ & 0.346 & 0.337 & 2.6 \\
\hline
\end{tabular}

cars on the bridge. The windproof guardrail is necessary to build bridge protection facilities to reduce the impact of crosswinds.

Hence, in the numerical simulation model, a model of the guardrail is placed on the left side of the car to simulate the facility of bridge, and the car driving velocity and the crosswind velocity are, respectively, set $120 \mathrm{~km} / \mathrm{h}$ and $24 \mathrm{~m} / \mathrm{s}$ as the initial conditions. The model is shown in Figure 5.

According to the automobile industry standard, the lateral acceleration when a car begins to roll over is called

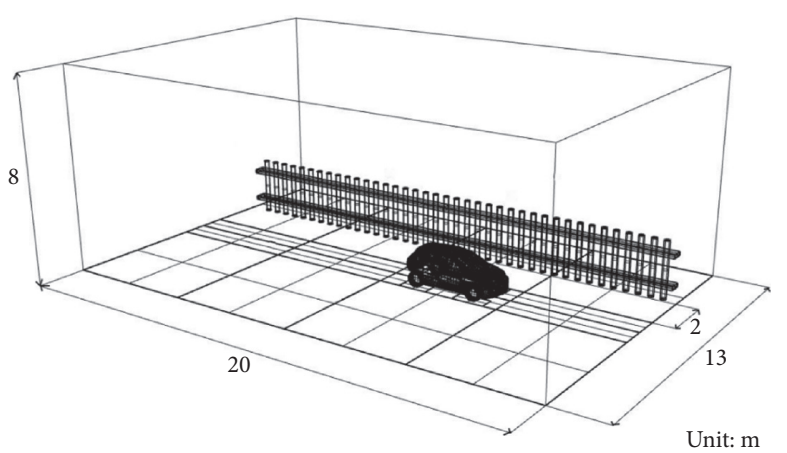

Figure 5: Model of the calculation domain.

the rollover threshold. This value is commonly used to estimate a car's rollover resistance ability. The rollover threshold can be identified by the automobile industry standard:

$$
\frac{a_{y}}{g}=\frac{B}{2 h}+\beta .
$$

For the rollover of cars with suspensions, the rollover threshold can be determined by the following equation:

$$
\frac{a_{y}}{g}=0.95 \frac{B}{2 h}
$$

where $a_{y}$ represents the lateral acceleration (units: $\mathrm{m} / \mathrm{s}^{2}$ ), $g$ represents the gravitational acceleration (units: $\mathrm{m} / \mathrm{s}^{2}$ ), $B$ represents the track width (units: $\mathrm{m}$ ), $h$ represents the car's centroid height (units: $\mathrm{m}$ ), and $\beta$ is the ramp angle.

When the car is on a cross-sea bridge, the ramp angle can be neglected. Equation (13) can be simplified to

$$
\frac{a_{y}}{g}=\frac{B}{2 h} \text {. }
$$

The value of rollover threshold from equation (14) is usually higher than the actual value.

In this paper, the track width of the test car is $1.41 \mathrm{~m}$, the total weight of the whole car model is $1135 \mathrm{~kg}$, and the centroid height is set between 0.51 and $0.58 \mathrm{~m}$. Based on the rollover threshold set between 1.1 and $1.5 \mathrm{~g}$, the crosswind force of the rollover of the car can be given as 12235-16684N.

\section{Analysis and Discussion}

Figure 5 shows the entire flow field domain. The front boundary and left boundary in the numerical simulation model are as the velocity inlets. The air velocity of the front boundary inlet represents the relative velocity of car, and the air velocity of the left boundary inlet represents the crosswind velocity. The back boundary and the right boundary are as the pressure outlets.

The results of the different performed simulations are shown and analyzed. The different air flows can be produced by different distances, heights, and diameters of the upright bar of the windproof guardrail on bridge, and the influence of which are discussed. Some 
visualizations of the flow field around the car are presented, and the pressure, the lateral force, and the lift force over the car are compared with the different case results.

4.1. Influences of the Porosity. The porosity is calculated by the opening part area divided by the overall area of the guardrail model. The height of the bridge guardrail is set $2.244 \mathrm{~m}$, and the diameter of the upright bar of the bridge guardrail is set $0.236 \mathrm{~m}$. The distance between the axes of adjacent upright bar of the bridge guardrail is set $0.5 \mathrm{~m}$, $0.75 \mathrm{~m}, 1 \mathrm{~m}$, and $1.5 \mathrm{~m}$, respectively, and the different porosities of the bridge guardrail are calculated, which are $35.8 \%, 52.1 \%, 61.8 \%$, and $72.8 \%$.

Figure 6 shows that the pressure distributions on the car with different porosities under the crosswind. These distributions indicate that the positive pressure is mainly on the near guardrail side of the car, especially on the front of the left side and on the back of the right side of the car, which are relatively higher than the other area of the car. With the increase in porosity of the bridge guardrail, the area of the positive pressure on the left side of the car increases. The negative pressures distributed on the front of the right side and the back of the left side of the car are also relatively higher. The difference between the positive pressure and the negative pressure is the primary cause of the car lateral offset.

The lateral force and the lift force on the near guardrail side of the car are shown in Table 2. It is observed that the lateral force increases as the porosity increases from $35.8 \%$ to $61.8 \%$; it slightly decreases with the porosity from $61.8 \%$ to $72.8 \%$, and the lift force of the car increases as the porosity increases from $52.1 \%$ to $72.8 \%$, and it decreases with the porosity from $35.8 \%$ to $52.1 \%$. Obviously, if the lateral force and the lift force are too large, the car will roll over very easily. Therefore, compared with others porosities, when the porosity is $35.8 \%$, the lateral force and the lift force are smaller; in other words, the car will be relatively stable.

4.2. Influences of the Guardrail Height. The diameter of the upright bar of the bridge guardrail is maintained as $0.236 \mathrm{~m}$, and the porosity is $35.8 \%$; the height of the bridge guardrail is set from $1 \mathrm{~m}$ to $2.5 \mathrm{~m}$ with an interval of $0.125 \mathrm{~m}$, and there are 13 different heights, respectively, as $1 \mathrm{~m}, 1.125 \mathrm{~m}, 1.25 \mathrm{~m}$, $1.375 \mathrm{~m}, 1.5 \mathrm{~m}, 1.625 \mathrm{~m}, 1.75 \mathrm{~m}, 1.875 \mathrm{~m}, 2 \mathrm{~m}, 2.125 \mathrm{~m}$, $2.25 \mathrm{~m}, 2.375 \mathrm{~m}$, and $2.5 \mathrm{~m}$. The different heights of the bridge guardrail make the characteristics of flow field around the car different, the distribution of pressure on the car different, and thus the lateral force and lift force on the car are also different.

Firstly, based on analysis of the characteristics of flow field around the car, the turbulent characteristics of the crosswind have a remarkable influence on the entire flow field. Here, the cross section of the car is intercepted to show the changes of the flow field, and the flow fields with 4 different guardrail heights, respectively, as $1 \mathrm{~m}, 1.5 \mathrm{~m}, 2 \mathrm{~m}$, and $2.5 \mathrm{~m}$ are shown in Figure 7.

It is observed that with the increase in guardrail height, the turbulent area of flow field increases continuously. The flow field of the car under the guardrail height being $1 \mathrm{~m}$ is significantly different from that under the other three guardrail heights conditions. When the guardrail height is $1 \mathrm{~m}$, the airflow in the top area of the car is almost unaffected by the guardrail and is still flowing at $24 \mathrm{~m} / \mathrm{s}$. Most of the turbulence is concentrated in the area of lower the leeward side of the car and upper the windward side of the car, and the airflow of lower the leeward side of the car is more turbulent than that of upper the windward side. The whole leeward side of the car is turbulent under the other three guardrail heights.

Secondly, based on analysis of the pressure distributions on the car, the pressure distributions with 4 different guardrail heights, respectively, as $1 \mathrm{~m}, 1.5 \mathrm{~m}, 2 \mathrm{~m}$, and $2.5 \mathrm{~m}$ are shown in Figure 8. It shows that when the guardrail height is $1 \mathrm{~m}$, the pressure of the windward side of the car is the largest, and the car is also the most affected by crosswind loads.

Thirdly, based on analysis of the lateral force and lift force on the car, Figure 9 shows that the lateral force and lift force on the car with 13 different guardrail heights. It is observed that the values of the lateral force and the lift force are maximum when the guardrail height is $1 \mathrm{~m}$, and then the values of the lateral force and the lift force have a decreasing tendency with increase in the guardrail height. The values of the lateral force and the lift force reach relatively minimum when the guardrail height is in a range of $1.5 \mathrm{~m}$ to $1.625 \mathrm{~m}$.

That is, when the guardrail height is $1 \mathrm{~m}$, the guardrail height is less than the height of the car, and the state of the car is the most unstable. When the guardrail height is in a range of $1.5 \mathrm{~m}$ to $1.625 \mathrm{~m}$, the car is relatively safe.

4.3. Influences of the Reynolds Number. The guardrail height is set to $1 \mathrm{~m}$, which has the greatest impact on the car. The upright bars of the bridge guardrail are circular; at the same time, the distance between the circumference of the adjacent upright bar of the guardrail is kept unchanged at $0.2 \mathrm{~m}$. The different $R_{e}$ numbers can be obtained by setting different diameters of the upright bar of the guardrail. The diameter of the upright bar of the guardrail is, respectively, set as $0.15 \mathrm{~m}$, $0.2 \mathrm{~m}, 0.25 \mathrm{~m}, 0.3 \mathrm{~m}, 0.35 \mathrm{~m}$, and $0.4 \mathrm{~m}$, and there are 6 different diameters to different sizes, and the corresponding 6 different Reynolds numbers are $2.63 e+5,3.51 e+5$, $4.39 e+5,5.27 e+5,6.15 e+5$, and $7.03 e+5$.

The distribution of vorticities with 6 different Reynolds numbers is shown in Figure 10. With the increase in diameter of the upright bar of the guardrail, the number of the upright bar of the guardrail decreases and the Reynolds numbers increase. The crosswind flow passes through the upright bar of the guardrail, blows to the left windward side of the moving car, and then bypasses around the car, making a large number of small vortex gathering on the rear of the right leeward side of the car. When the Reynolds number $R_{e}$ is smaller, the flow field pass through the guardrail is laminar flow, and the pressure on the windward side of the car is higher. With the increase in Reynolds number, the flow field passes through the guardrail and gradually forms into turbulence. When the Reynolds number increases to 


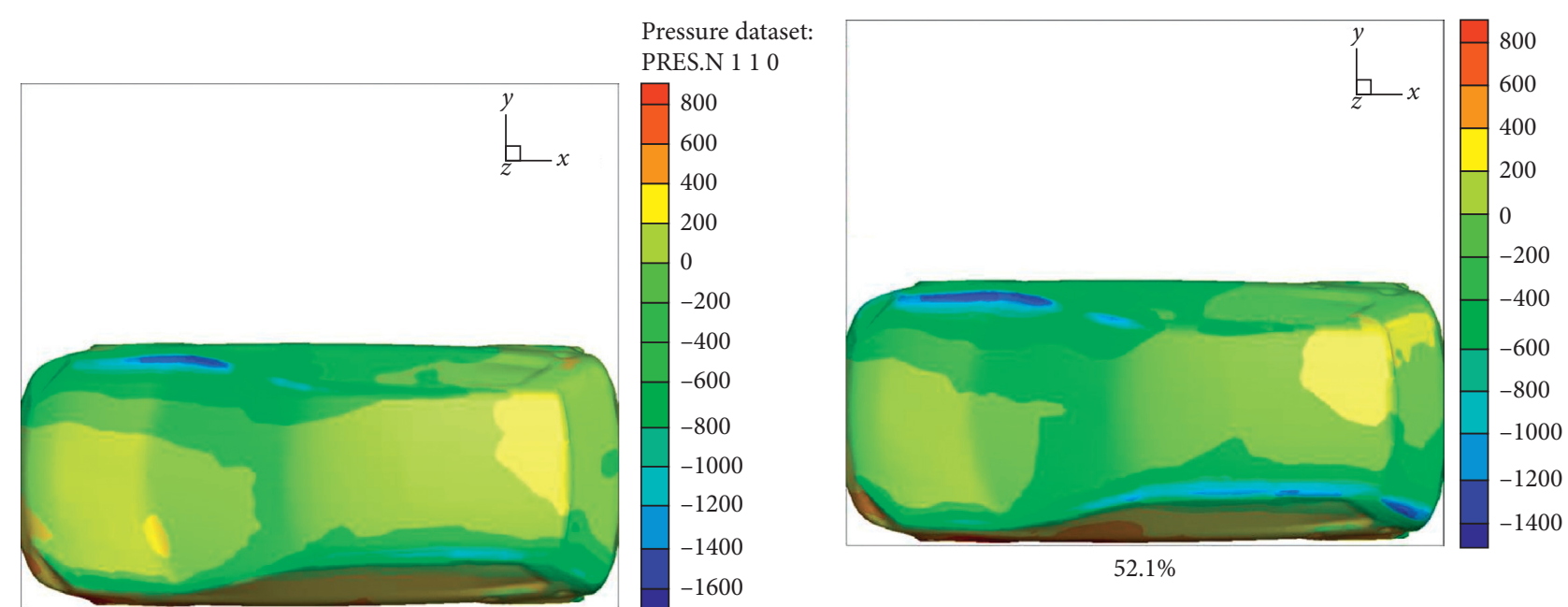

(a)

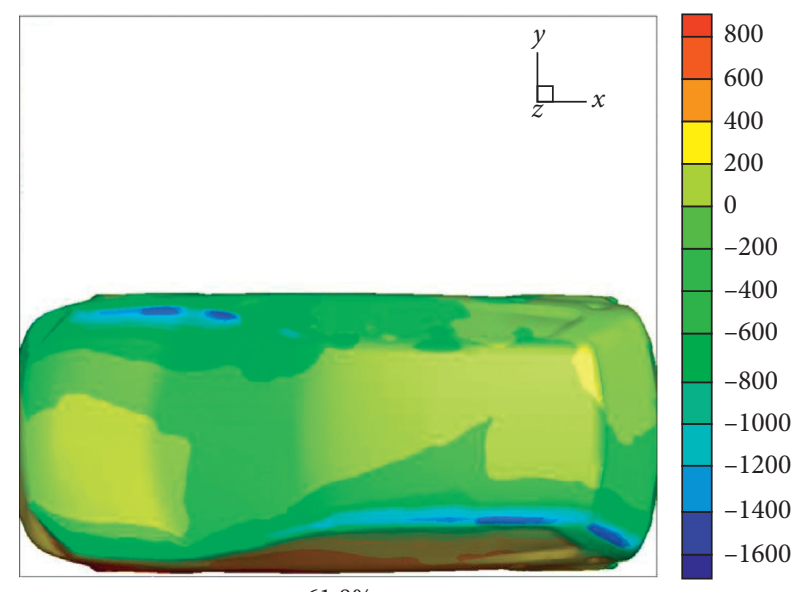

$61.8 \%$

(c) (b)

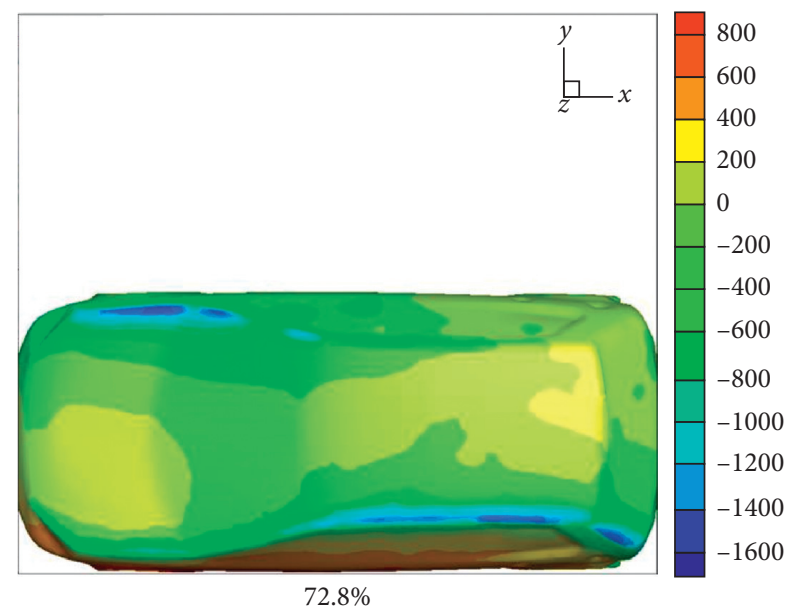

(d)

Figure 6: The distribution of pressure on the car with different porosities.

TABLE 2: Lateral force and lift force on the car with different porosities.

\begin{tabular}{lcc}
\hline Porosity & Lateral force $(N)$ & Lift force $(N)$ \\
\hline $35.8 \%$ & 1794.07 & 992.35 \\
$52.1 \%$ & 1943.01 & 854.06 \\
$61.8 \%$ & 2057.03 & 1059.23 \\
$72.8 \%$ & 2051.48 & 1158.40 \\
\hline
\end{tabular}

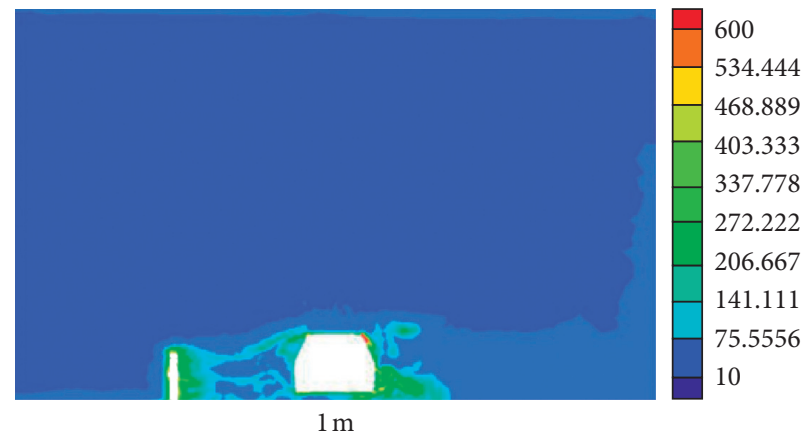

(a)

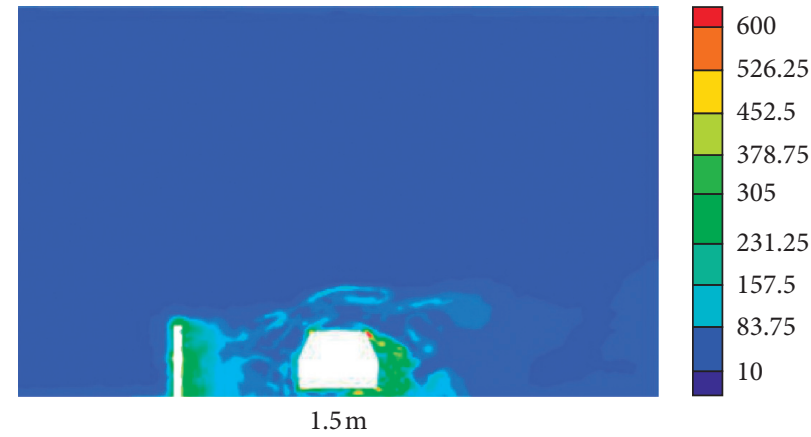

(b)

Figure 7: Continued. 


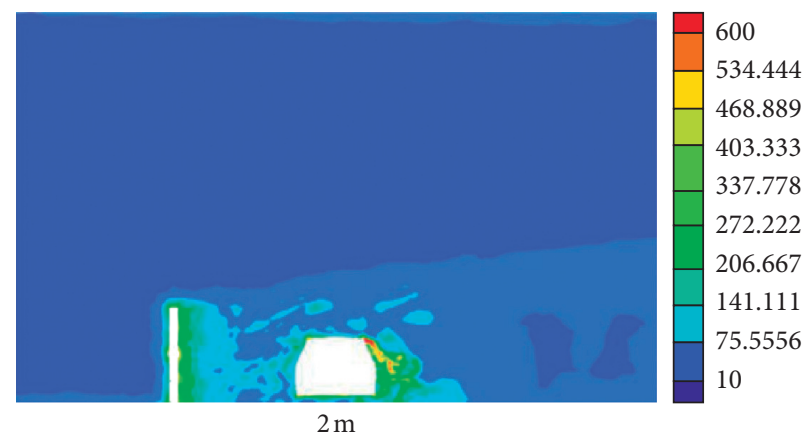

(c)

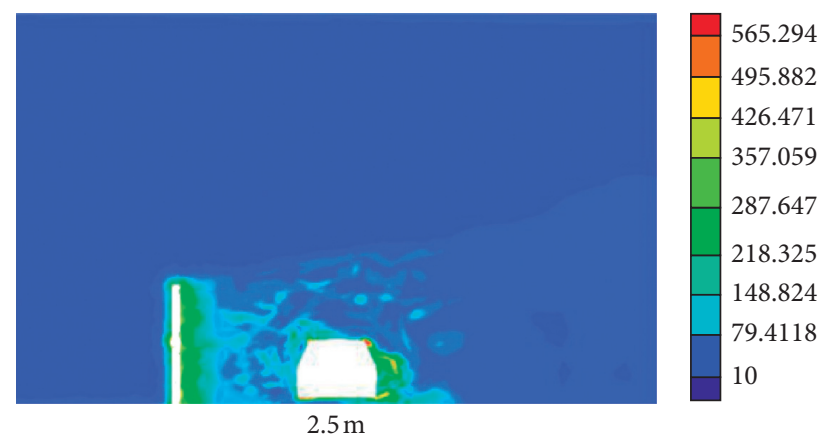

(d)

Figure 7: The flow fields with different guardrail heights.

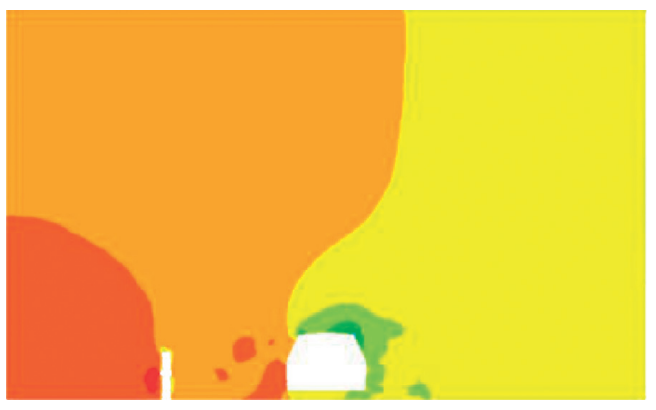

$1 \mathrm{~m}$

(a)

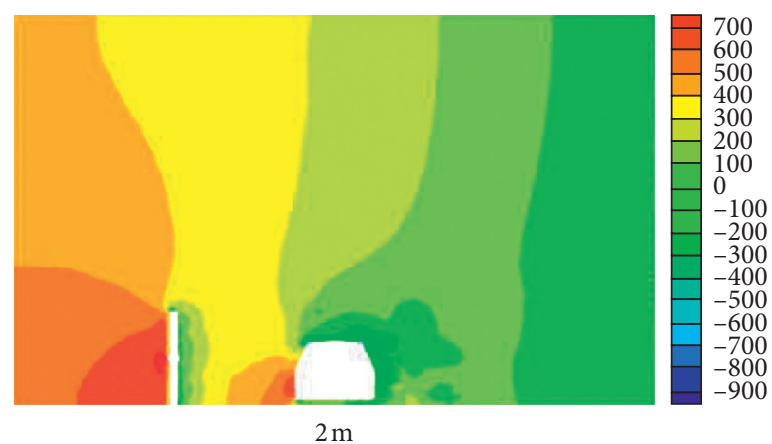

(c)

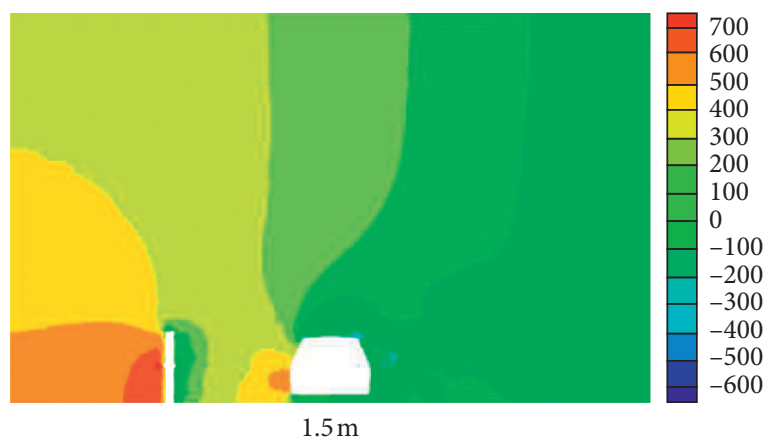

(b)

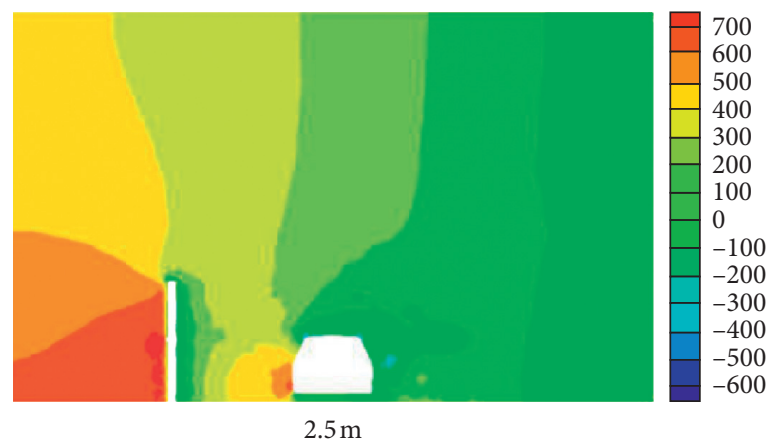

(d)

Figure 8: The pressure distributions with different guardrail heights.

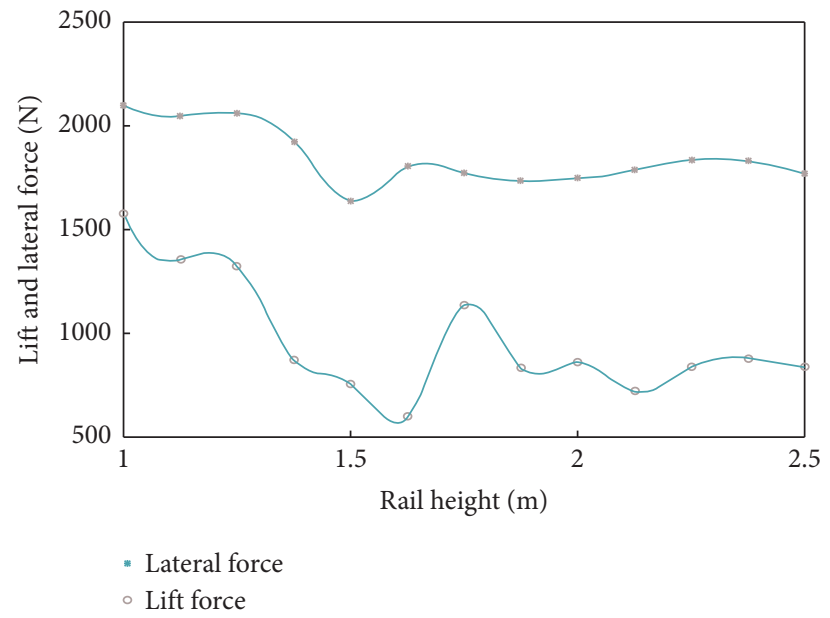

Figure 9: The curve of lateral force and lift force with different guardrail heights. 


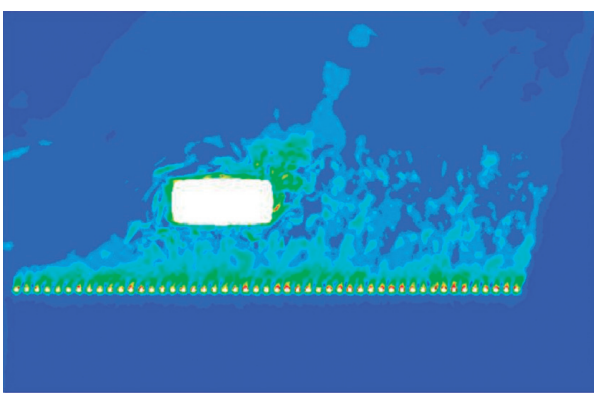

$2.36 e+5$

(a)

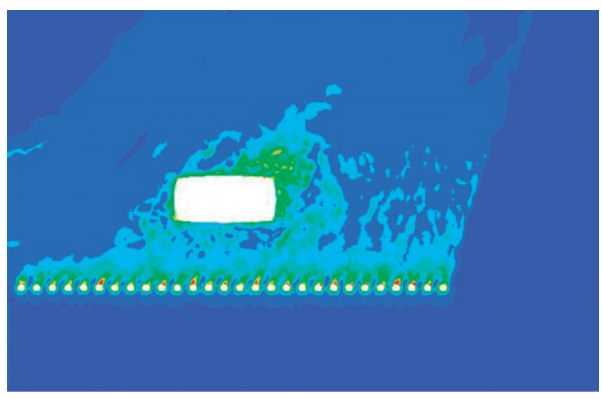

$4.39 e+5$

(c)

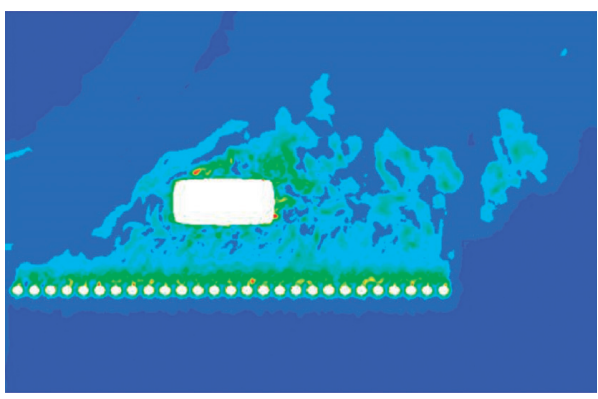

$6.15 e+5$

(e)

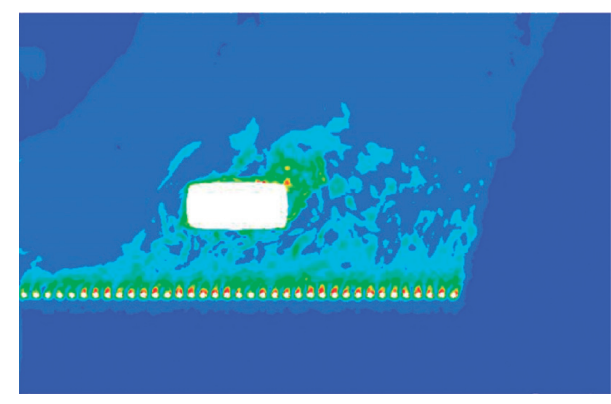

$3.51 e+5$

(b)

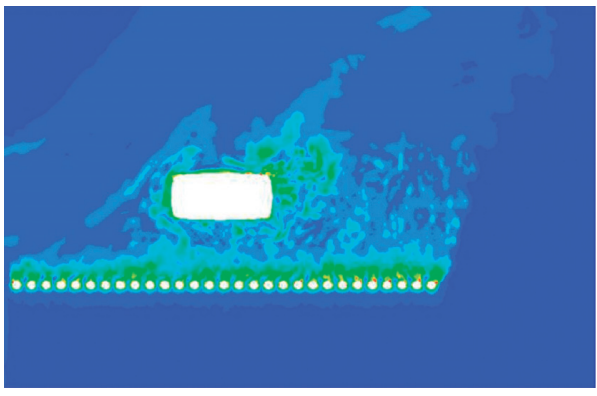

$5.27 e+5$

(d)

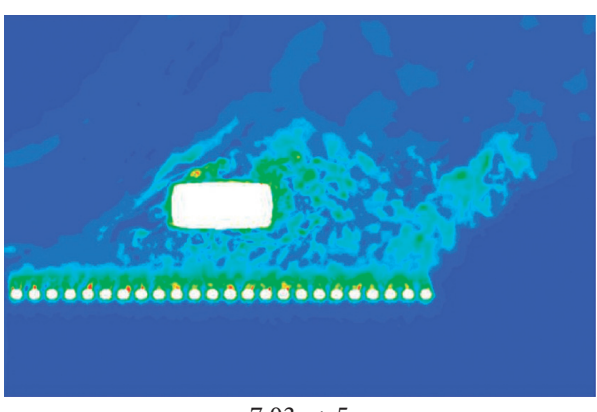

$7.03 e+5$

(f)

FIGURE 10: Distribution of vorticities with different Reynolds numbers.

TABLE 3: Lateral force and lift force with different $R_{e}$ numbers.

\begin{tabular}{lccc}
\hline Upright bar diameter $(\mathrm{m})$ & $R_{e}$ number & Lateral force $(N)$ & Lift force $(N)$ \\
\hline 0.15 & $2.63 e+5$ & 2399.33 & 1475.63 \\
0.20 & $3.51 e+5$ & 2615.24 & 2059.39 \\
0.25 & $4.39 e+5$ & 2534.40 & 1762.40 \\
0.30 & $5.27 e+5$ & 2239.34 & 1919.91 \\
0.35 & $6.15 e+5$ & 2242.86 & 1617.17 \\
0.40 & $7.03 e+5$ & 2022.38 & 1177.59 \\
\hline
\end{tabular}

$7.03 e+5$, the flow field passes through the guardrail directly forming turbulence; the turbulence dissipates some of the energy of the crosswind, which results in relatively lower pressure on the windward side of the car.

The values of the lateral force and the lift force with different $R_{e}$ numbers are shown in Table 3. With the increase in Reynolds number from $2.63 e+5$ to $3.51 e+5$, the values of the lateral force and the lift force increase and reach the maximum. With the increase in Reynolds number from $3.51 e+5$ to $7.03 e+5$, the values of the lateral force and the lift force have decreasing tendency at the whole. When the Reynolds number increases to $7.03 e+5$, the values of the lateral force and the lift force are minimum; in other words, the car will be relatively safe at this time.

\section{Conclusions}

In this paper, the large eddy simulation method is used to study the flow field characteristics and safety of the car on the bridge under the turbulent crosswind. The numerical 
simulation model is established by referring to the Donghai Bridge, and the correctness of the car model is validated by combining with the data of the wind tunnel test. The influence of factors such as the porosity and height of the bridge guardrail and the Reynolds number of airflow on the flow field characteristics is analyzed. The research results showed the following:

(1) According to the calculation of 4 different porosities, with the increase in the porosity of the bridge guardrail, the windward pressure of the car increases, and the lateral force and lift force of the car also gradually increase. $35.8 \%$ is a more appropriate porosity rate of the bridge guardrail.

(2) Under the condition of constant porosity, the cases of 13 kinds of bridge guardrail heights are calculated. As the height of guardrail increases, the turbulence area of flow field increases continuously. When the height of guardrail is greater than the height of the car, the whole leeward of the car cross section is turbulence.

(3) When the guardrail height is less than the height of the car, which is 1 meter, the windward pressure, the lateral force, and the lift force of the car are the maximum, which is a relatively unsafe condition. When the range of the guardrail height is from 1.5 to 1.625 meters and the lateral force and lift force are smaller, the car is relatively safe.

(4) On the condition that the height of the guardrail remains unchanged at 1 meter, the cases of 6 different Reynolds numbers are calculated. With the increase in Reynolds number, the flow field passes through the guardrail and gradually forms turbulence. The area of turbulence is concentrated in the rear of the leeward of the car's overhead plane.

(5) When Reynolds number is $3.51 e+5$, the lateral force and the lift force are the largest, which means the car is relatively unsafe. After that, with the increase in Reynolds number, the lateral force and lift force gradually decrease, and the safety of the car gradually improves.

\section{Data Availability}

The simulation data used to support the findings of this study are included within the article. The simulation data used to support the findings of this study were supplied by CMVTC company under license and so cannot be made freely available. Requests for access to these data should be made to Juyue Ding (juyueding@163.com). The wind velocity test data used to support the findings of this study are available from the corresponding author upon request.

\section{Conflicts of Interest}

The authors declare that they have no conflicts of interest.

\section{References}

[1] J. P. Howell, "The side load distribution on a rover 800 saloon car under crosswind conditions," Journal of Wind Engineering and Industrial Aerodynamics, vol. 60, pp. 139-153, 1996.

[2] L. D. Zhu, L. Li, Y. L. Xu, and Q. Zhu, "Wind tunnel investigations of aerodynamic coefficients of road vehicles on bridge deck," Journal of Fluids and Structures, vol. 30, pp. 35-50, 2012.

[3] R. Huang, S. J. Zheng, Z. S. Liu, and T. Y. Ng, "Recent advances of the constitutive models of smart materialshydrogels and shape memory polymers," International Journal of Applied Mechanics, vol. 12, no. 2, Article ID 2050014, 2020.

[4] Y. Q. Ma, Y. K. Zhou, Y. Dong, and W. Feng, "Hybrid natural element method for elastic large deformation problems," International Journal of Applied Mechanics, vol. 8, no. 4, Article ID 1650044, 2016.

[5] J. Cheng, "Analysis of commercial land leasing of the district governments of Beijing in China," Land Use Policy, vol. 100, Article ID 104881, 2021.

[6] J. Cheng, "Data analysis of the factors influencing the industrial land leasing in Shanghai based on mathematical models," Mathematical Problems in Engineering, vol. 2020, Article ID 9346863, 17 pages, 2020.

[7] J. Wang and F. Sun, "A hybrid variational multiscale elementfree Galerkin method for convection-diffusion problems," International Journal of Applied Mechanics, vol. 11, no. 7, Article ID 1950063, 2019.

[8] Y. Deng, X. He, and Y. Dai, "The improved interpolating complex variable element free Galerkin method for twodimensional potential problems," International Journal of Applied Mechanics, vol. 11, no. 10, Article ID 1950104, 2019.

[9] Z. Liu, G. Wei, and Z. Wang, "Numerical analysis of functionally graded materials using reproducing kernel particle method," International Journal of Applied Mechanics, vol. 11, no. 6, Article ID 1950060, 2019.

[10] B. Wang and X. Fan, "Ground flutter simulation test based on reduced order modeling of aerodynamics by CFD/CSD coupling method," International Journal of Applied Mechanics, vol. 11, no. 1, Article ID 1950008, 2019.

[11] Y. Maruyama and F. Yamazaki, "Driving simulator experiment on the moving stability of an automobile under strong crosswind," Journal of Wind Engineering and Industrial Aerodynamics, vol. 94, no. 4, pp. 191-205, 2006.

[12] D. Rocchi, L. Rosa, E. Sabbioni, and M. Sbrosi, "A numericalexperimental methodology for simulating the aerodynamic forces acting on a moving vehicle passing through the wake of a bridge tower under cross wind," Journal of Wind Engineering and Industrial Aerodynamics, vol. 94, no. 4, pp. 256-265, 2012.

[13] E. Sabbioni, M. Sbrosi, and D. Rocchi, "Dynamic response of vehicle-driver couple to the aerodynamic loads due to the crossing of a bridge tower wake," SAE International Journal of Commercial Vehicle, vol. 5, no. 1, pp. 83-93, 2012.

[14] F. Cheli, P. Belforte, S. Melzi, E. Sabbioni, and G. Tomasini, "Numerical-experimental approach for evaluating cross-wind aerodynamic effects on heavy vehicles," Vehicle System Dynamics, vol. 44, no. 1, pp. 791-804, 2006.

[15] F. Cheli, R. Corradi, E. Sabbioni, and G. Tomasini, "Wind tunnel tests on heavy road vehicles: cross wind induced loads-Part1," Journal of Wind Engineering and Industrial Aerodynamics, vol. 5, no. 1-10, pp. 1000-1010, 2011. 
[16] M. S. Cheung and B. Y. B. Chan, "Operational requirements for long-span bridges under strong wind events," Journal of Bridge Engineering, vol. 15, no. 2, pp. 131-143, 2010.

[17] R. Sigbjörnsson and J. T. Snæbjörnsson, "Probabilistic assessment of wind related accidents of road vehicles: a reliability approach," Journal of Wind Engineering and Industrial Aerodynamics, vol. 74, pp. 1079-1090, 1998.

[18] Y. L. Xu and W. H. Guo, "Dynamic behavior of high-sided road vehicles subject to a sudden cross wind gust," Wind and Structure, vol. 6, no. 5, pp. 325-346, 2003.

[19] B.-C. Chen and H. Peng, "Differential-braking-based rollover prevention for sport utility vehicles with human-in-the-loop evaluations," Vehicle System Dynamics, vol. 36, no. 4-5, pp. 359-389, 2010.

[20] M. Krid and F. Benamar, "Design and control of an active anti-roll system for a fast rover," in Proceedings of the Intelligent Robots and Systems (IROS), IEEE/RSJ International Conference, Paris, France, October 2011.

[21] J. Ackermann and D. Odenthal, "Damping of vehicle roll dynamics by gain scheduled active steering," in Proceedings of the European Control Conference(ECC), Karlsruhe, Germany, July 2000.

[22] M. C. Good and P. N. Joubert, "The form drag of two-dimensional bluff-plates immersed in turbulent boundary layers," Journal of Fluid Mechanics, vol. 31, no. 3, pp. 547-582, 1968.

[23] K. G. Ranga Raju, R. J. Garde, S. K. Singh, and N. Singh, "Experimental study on characteristics of flow past porous fences," Journal of Wind Engineering and Industrial Aerodynamics, vol. 29, no. 1-3, pp. 155-163, 1988.

[24] T. Tunay, E. Firat, and B. Sahin, "Experimental investigation of the flow around a simplified ground vehicle under effects of the steady crosswind," International Journal of Heat and Fluid Flow, vol. 71, pp. 137-152, 2018.

[25] J. Smagorinsky, "General circulation experiments with the primitive equations," Monthly. Weather Review, vol. 91, no. 3, pp. 99-165, 1963. 